$82 ; 45 \%$ ), anhydrosis/hypohydrosis (44/82; 53.6\%), and cornea verticillata (40/62; $64.5 \%$ ). However, there was a significant delay to diagnosis of up to 51 years (median $18^{9 ; 27}$ years). Moreover, diagnosis was established by nationwide screening in dialysis units in $22 / 82(26.8 \%)$ patients or by family screening in 34 / $82(41.4 \%)$ patients. At the time of diagnosis, patients usually presented with a clinical picture of systemic disease with mild to moderate proteinuria with or without impairment of kidney function (70/82; 85.4\%), left ventricular hypertrophy (56/ $82 ; 68.3 \%)$, white matter lesions on brain MRI $(38 / 72 ; 52.8 \%)$, and/or a history of stroke $(15 / 82 ; 18.3 \%)$. Twenty six of 82 patients $(31.7 \%)$ previously had at least one diagnosis of rheumatic disease (Table 1). The common causes for referral to rheumatologist were skin rash and neuropathic pain. In 6 of 26 patients $(23.1 \%)$, the latter was initially misdiagnosed as joint pain. The possible causes of diagnostic errors included also 'genuine' arthralgia $(6 / 26 ; 23.1 \%)$, episodes of unexplained fever $(13 / 26 ; 50 \%)$, Raynaud phenomenon $(2 / 26 ; 7.7 \%)$, and the laboratory markers of inflammation $(11 / 26 ; 42.3 \%)$.

Abstract SAT0627 - Table 1. 'Rheumatic' diagnoses in Fabry patients

\begin{tabular}{lc}
\hline Misdiagnoses & Number of patients \\
\hline Vasculitis* & $6(7.3 \%)$ \\
Arthritis* & $5(6.1 \%)$ \\
Osler-Weber-Rendu disease & $4(4.9 \%)$ \\
Rheumatic fever & $4(4.9 \%)$ \\
Systemic lupus erythematosus & $3(3.7 \%)$ \\
Familial Mediterranean fever & $1(1.2 \%)$ \\
\hline
\end{tabular}

Familial Mediterranean fever

$1(1.2 \%)$

Note: *Vasculitides included IgA-vasculitis, Behcet disease, etc. ${ }^{* *}$ Arthritides included

rheumatoid arthritis, juvenile rheumatoid arthritis and osteoarthritis.

Conclusions: Practicing rheumatologists should be aware of FD, given a high occurrence of diagnostic errors. The clues to correct diagnosis include a history of typical symptoms (i.e. neuropathic pain, angiokeratoma, hypohydrosis) from childhood or adolescence and/or the presence of typical manifestations in family members. Notably, FD can initially present as an autoinflammatory disorder with episodes of joint pain and unexplained fever associated with the laboratory markers of inflammation.

Disclosure of Interest: None declared

DOI: 10.1136/annrheumdis-2018-eular.2757

\section{SAT0628 A RETROSPECTIVE OBSERVATIONAL STUDY OF AZATHIOPRINE MAINTENANCE THERAPY ON BEHCET'S DISEASE WITH VASCULAR INVOLVEMENT}

S. Girgin ${ }^{1}$, S. Yurumez ${ }^{2}$, A. Omma ${ }^{2}$, C. Bes ${ }^{1}$, S. Celik ${ }^{1}$, N. Alpay Kanitez ${ }^{1}$. ${ }^{1}$ Bakirkoy Dr. Sadi Konuk Training and Research Hospital, istanbul; ${ }^{2}$ Ankara Numune Training and Research Hospital, Ankara, Turkey

Background: Vascular disease which has potential to involve both arteries and veins of all size is one of the major causes of mortality and morbidity in Behçet's disease (BD). There is no controlled studies for the immunosuppressive (IS) therapy in vascular involvement of BD. For the induction and/or maintenance therapy, azathioprine (AZA) is widely used as a corticosteroid tapering IS agent in vascular $\mathrm{BD}$ although there are many different clinical presentation.

Objectives: The purpose of this study to investigate relapse rate and the clinical factors affecting it during AZA maintenance therapy.

Methods: Consecutive BD patients with a documentation for arterial or venous involvement were evaluated from two rheumatology centre between JanuarySeptember 2017. Patients who have been treated for at least 3 months after the complete or partial remission were included to study. The baseline clinical and laboratory findings, treatment protocol, first vascular relapse time and adverse events were obtained medical records. Long-term outcome and factor associated with vascular relapse were assessed.

Results: Totally 78 patients were included to the study and majority of them [59 $(\% 75.6)$ ] was male. The mean age \pm SD of the patients was $37.5 \pm 9$ years. Clinical characteristics of patients are seen in table 1. The median duration of maintenance therapy with AZA was 25 ( $\min 3-\max 144$ ) months and the mean dose $\pm S D$ of $A Z A$ was found as $1.7 \pm 0.3 \mathrm{mg} / \mathrm{kg} /$ day. AZA was withdrawn in $4(\%$ 5.1) patients because of adverse events. Twenty patients (\%25.6) were receiving anti-coagulant therapy. Vascular relapse was observed in $14(\% 17.9)$ patients. In relapsing group, arterial involvement and uveitis was higher statistically ( $\mathrm{p}=0.014$ and 0.045 respectively). In regression analysis, arterial involvement was independent risk factor for relapse $(p=0.016)$. The percentage of relapses was calculated as\%39 (7/18) in patient subgroup with arterial involvement. Relapse free survival rates according to involving vessel were seen in figure 1.

Abstract SAT0628 - Table 1. Clinical characteristics of vascular Behçet's Disease $(n=78)$

\begin{tabular}{lc}
\hline The mean age \pm SD & $37.5 \pm 9.2$ \\
\hline Male gender n (\%) & $59(76)$ \\
Genital ulcer n (\%) & $49(63)$ \\
Skin lesions n (\%) & $44(57)$ \\
Paterji positivity n (\%) & $29(38)$ \\
Uveitis n (\%) & $17(22)$ \\
Musculoskeletal involvement n (\%) & $15(20)$ \\
CNS involvement $\mathrm{n}(\%)$ & $1(1.2)$ \\
GIS involvement $\mathrm{n}(\%)$ & $1(1.2)$ \\
Venous involvement $\mathrm{n}(\%)$ & $67(86)$ \\
Arterial involvement $\mathrm{n}(\%)$ & $18(24)$ \\
\hline
\end{tabular}

SD: Standart deviation, CNS: Central nervous system, GIS: Gastrointestinal system

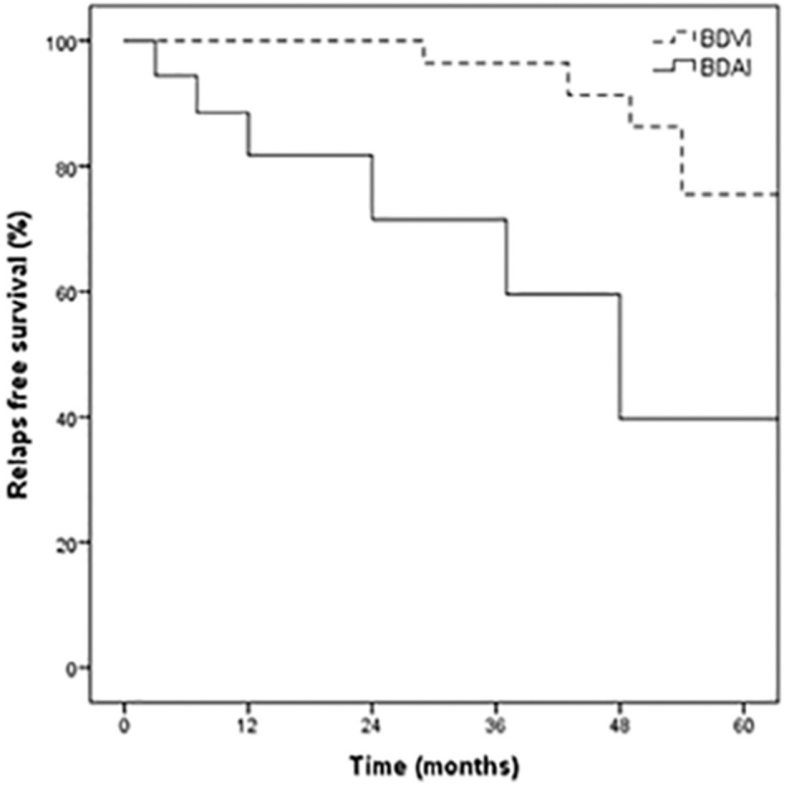

Abstract SAT0628 - Figure 1. Relapse free survival rates according to involving vessels in patients with Behçet's disease (BD) by using Kaplan-Meier method (BDVI: Behçet's disease with venous involvement, BDAl: Behçet's disease with arterial involvement, $p=0.001$ by logrank test).

Conclusions: According to our study, AZA is seen as safe in maintenance therapy of BD with vascular involvement, however it can be said that the relapse rate is not favourable especially in patients with arterial involvement. Vascular involvement is considered as related to endotel inflammation resulting BD activity and the effect of anti-coagulant therapy is still controversial. TNF inhibitors or other immu nosuppressant may be alternative to AZA for maintenance therapy with the support of randomized-controlled studies.

Disclosure of Interest: None declared

DOI: 10.1136/annrheumdis-2018-eular.4090

\section{SAT0629 IGG4 RELATED CASTLEMAN'S DISEASE OR "SECONDARY" IGG4 RELATED DISEASE OF MULTICENTER CASTLEMAN'S DISEASE?}

X. Zhang, P. zhang, L. peng, Y. fei, W. zhang, R. feng, W. zhang. Rheumatology, Peking Union Medical Colledge, BeiJing, China

Background: It's widely accepted that a diagnosis of IgG4-related disease (IgG4-RD) can be made under a premise of rule out a series of disease including Castleman's disease (CD). Clinically, the two diseases may share similar clinical manifestations, such as multiple organ involvement. Pathologically, in some cases with CD, IgG4 positive plasma cell infiltrations are also evident. Otherwise, IgG4-RD may pathologically exhibits CD-like feature[. ${ }^{1-3}$ 
Objectives: When the histopathology coincides with the diagnosis of both IgG4$\mathrm{RD}$ and $\mathrm{CD}$, it is hard to depart the two disease entity utterly. It's unknown weather it is IgG4 related CD or "secondary" IgG4-RD of multicentric CD, here we call it IgG4-CD provisionally. To our knowledge, no comparative study of IgG4-CD and IgG4-RD has yet been published. In this study, we aim to review the clinical feature of lgG4-CD.

Methods: This study is based on a retrospective analysis of a prospectively acquired database. IgG4-CD were defined histopathologically in patients who fulfilled the diagnosis of both $\lg G 4-R D$ and CD. Forty five definate lgG4-RD patients were recruited as control. Clinical features including organ involvement, serum lgG4, IgG, IgE, ESR and CRP levels of all the participants were collected and analysed statistically.

Results: Fifteen patients (2.8\%) out of 534 patients with lgG4-RD in China's largest prospective IgG4-RD and Mimicry cohort fulfilled the definition of IgG4-CD. There were 14 males and 1 female, mean age was $47 \pm 18$ years, and the median disease duration before diagnosis was 12 (1-132) months. Eight patients have allergic history. IgG4-CD patients had more lymph node involvement (100\% vs $57.8 \%, \mathrm{p}<0.01$ ), while IgG4-RD patients had more submandibular (33.3\% vs $77.1 \%, p<0.01)$ and parotid gland $(13.3 \%$ vs $40.9 \%, p<0.05)$ affected. IgG4-CD patients had significantly higher levels of ESR $(\mathrm{mm} / \mathrm{h}), \mathrm{CRP}(\mathrm{mg} / \mathrm{L}), \lg \mathrm{G}(\mathrm{g} / \mathrm{L})$, $\lg 1_{1}(\mathrm{~g} / \mathrm{L}), \lg \mathrm{g} 3(\mathrm{~g} / \mathrm{L}), \lg \mathrm{l} 4(\mathrm{mg} / \mathrm{dL})$, and $\lg \mathrm{E}(\mathrm{g} / \mathrm{L})[76.50$ (5.00-129.00) vs 17.00 (2.00-89.00), $5.39(0.54-134.00)$ vs $1.6(0.08-113.74), 35.28(9.76-69.00)$ vs 19.36 (7.46-61.00), $11.2(6.84-41.00)$ vs 8.07 (4.08-16.70), $1.55(0.19-3.20)$ vs $0.53(0.09-2.00), 1590.00(133.00-6420.00)$ vs $1070.00(152.0-6100.00), 807.5$ (215.00-2967.00) vs 214.00 (20.40-2437.00), respectively. $\mathrm{p}<0.05)$. Except for one patient refused to receive drug therapy untreated, the remaining patients with IgG4-CD all received glucocorticoid (GC) treatment. Patients with multi-organ involvement or in severe inflammatory condition were treated with both GC and immunosuppressive agents, those who with active disease but resistant to above regimen accepted biologics such as rituximab. All patients with IgG4-CD exhibited favourable outcomes.

Conclusions: Both lgG4-RD and CD can involve multiple organs. There are a small group of patients who had clinical and pathological characteristics of both CD and IgG4-RD showed better clinical outcome. Long-term prognosis of these patients, the relationship of CD and IgG4-RD are waiting to be further elucidated.

\section{REFERENCES:}

[1] Ishida F, Kitano K, Kobayashi H, et al. Elevated IgG4 levels in a case with multicentric Castleman's disease. Br J Haematol 1997;99:981-982.

[2] Sasaki T, Akiyama M, Kaneko $Y$, et al. Distinct features distinguishing lgG4-related disease from multicentric Castleman's disease. RMD Open 2017;3(1):e000432.

Acknowledgements: None.

Disclosure of Interest: None declared

DOI: 10.1136/annrheumdis-2018-eular.3479

\section{SATURDAY, 16 JUNE 2018}

\section{Diagnostics and imaging procedures}

\section{SAT0630 \\ AGREEMENT BETWEEN PATIENT-REPORTED SWOLLEN AND TENDER JOINTS, CLINICAL EXAMINATION AND SYNOVITIS DETECTED BY ULTRASONOGRAPHY IN RHEUMATOID ARTHRITISPATIENTS AT THE TIME OF PATIENT- REPORTED FLARE}

D. Kuettel ${ }^{1,2}$, L. Terslev ${ }^{3}$, U. Weber ${ }^{1,2}$, M. Østergaard ${ }^{3}$, J. Primdahl ${ }^{1,2}$ R. Petersen ${ }^{1}$, M.A. Danielsen ${ }^{3}$, K. Hørslev-Petersen ${ }^{1,2}$. ${ }^{1}$ King Christian X's Hospital for Rheumatic Diseases, Graasten; ${ }^{2}$ Institute for Regional Health Research, University of Southern Denmark; ${ }^{3}$ Copenhagen Center for Arthritis Research (COPECARE), Copenhagen, Denmark

Background: In Rheumatoid Arthritis (RA), patient-reported tender joints (PrTJ) correlate better with clinical examination than patient-reported swollen joints (PrSJ). ${ }^{1}$ Clinical examination has inferior sensitivity to detect synovitis compared to ultrasonography (US). ${ }^{2}$ However, data is sparse about these findings at the time of patient-reported flare (PRFI).

Objectives: To investigate agreement between PrSJ, PrTJ, clinically detected swollen and tender joints (CSJ and CTJ,) and inflammation by Colour Doppler (CD) US in RA patients at the time of PRFI.

Methods: 80 consecutive rheumatoid-factor and/or anti-cyclic citrullinated peptide antibody positive RA patients with DAS28-CRP $<3.2$ and no swollen joints at baseline were during a one-year follow-up period requested to contact the hospital in case of a hand flare according to patients' perspective. At the flare visit, patients indicated PrSJ and PrTJ, and underwent examination for cSJ and cTJ, and US of bilateral wrists (wrist joints and six extensor tendon compartments), 1-5 metacarpophalangeal joints (MCP) and 1-5 proximal interphalangeal joints (PIP). CD synovitis and tenosynovitis were graded $0-3$ according to EULAR/OMERACT scoring system ${ }^{3}$ and joints and tendon sheaths with $C D>1$ were considered positive. Percentage agreement and Cohen's kappa were calculated between PrSJ PrTJ, cSJ, cTJ and CD in joints and tendon sheaths.

Results: Thirty-six percent $(29 / 80)$ of the RA patients reported a hand flare $(69 \%$ female, mean age 65 years, median DAS28-CRP 1.8, at baseline). At flare, mean $( \pm S D)$ number of PrSJ, cSJ, PrTJ, cTJ and CD positive joints were 2.7 (2.86), 1.5 (1.02), 4 (3.04), 4 (3.46) and 1.8 (1.31), respectively. For swelling, there was slightly superior agreement with CD for CSJ than for PrSJ, except for wrist tenosynovitis where patients agreed more frequently with $C D$ than clinical examination did (table 1). Highest percentage agreement was seen for PIP, followed by MCP. Agreement, as assessed by kappa, was poor to fair, ranging from -0.009 to 0.33 Swelling in MCP and PIP joints, by patients and clinicians, and swelling in the wrist by clinician showed better agreement with $\mathrm{CD}$ than tenderness did.

Abstract SAT0630 - Table 1. Concordance between patient-reported and clinically examined swollen and tender joints versus $C D$ at the time of patient-reported flare

\begin{tabular}{|c|c|c|c|c|c|c|c|}
\hline Joint & $\begin{array}{l}\text { No of joints. } \\
\text { examined }\end{array}$ & Comparison between & $+/+$ & $+/=$ & $-1+$ & 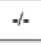 & $\begin{array}{c}\% \\
\text { agreement }\end{array}$ \\
\hline \multirow{8}{*}{ Wrist } & \multirow{8}{*}{$\mathrm{n}=58$} & $\begin{array}{l}\text { Clinical swelling vs } \\
\text { CD synovitis }\end{array}$ & 6 & 10 & 11 & 31 & 64 \\
\hline & & $\begin{array}{l}\text { Clinical swelling vs } \\
\text { CD tenosynovitis }\end{array}$ & 4 & 12 & 4 & 38 & 72 \\
\hline & & $\begin{array}{l}\text { Patient-reported swelling vs } \\
\text { CD synovitis }\end{array}$ & 5 & 13 & 12 & 28 & 57 \\
\hline & & $\begin{array}{l}\text { Patient-reported swelling vs } \\
\text { CD tenosynovitis }\end{array}$ & 6 & 12 & 2 & 38 & 76 \\
\hline & & $\begin{array}{l}\text { Clinical tenderness vs } \\
\text { CD synovitis }\end{array}$ & 5 & 11 & 12 & 30 & 60 \\
\hline & & $\begin{array}{l}\text { Clinical tenderness vs } \\
\text { CD tenosynovitis }\end{array}$ & 4 & 12 & 4 & 38 & 72 \\
\hline & & $\begin{array}{l}\text { Patient-reported tenderness vs } \\
\text { CD synovitis }\end{array}$ & 5 & 11 & 12 & 30 & 60 \\
\hline & & $\begin{array}{l}\text { Patient-reported tenderness vs } \\
\text { CD tenosynovitis }\end{array}$ & 5 & 11 & 3 & 39 & 76 \\
\hline \multirow{4}{*}{ MCP } & \multirow{4}{*}{$\mathrm{n}=290$} & $\begin{array}{l}\text { Clinical swelling vs } \\
\text { CD synovitis }\end{array}$ & 0 & 18 & 27 & 245 & 85 \\
\hline & & $\begin{array}{l}\text { Patient-reported swelling vs } \\
\text { CD synovitis }\end{array}$ & 3 & 34 & 24 & 229 & 80 \\
\hline & & $\begin{array}{l}\text { Clinical tenderness vs } \\
\mathrm{CD} \text { synovitis }\end{array}$ & 7 & 47 & 20 & 216 & 77 \\
\hline & & $\begin{array}{l}\text { Patient-reported tendemess vs } \\
\text { CD synovitis }\end{array}$ & 4 & 45 & 23 & 218 & 77 \\
\hline \multirow{4}{*}{ PIP } & \multirow{4}{*}{$\mathrm{n}=290$} & $\begin{array}{l}\text { Clinical swelling vs } \\
\text { CD synovitis }\end{array}$ & 0 & 8 & 9 & 273 & 94 \\
\hline & & $\begin{array}{l}\text { Patient-reported swelling vs } \\
\text { CD synovitis }\end{array}$ & 0 & 19 & 9 & 262 & 90 \\
\hline & & $\begin{array}{l}\text { Clinical tenderness vs } \\
\text { CD synovitis }\end{array}$ & 3 & 30 & 6 & 251 & 88 \\
\hline & & $\begin{array}{l}\text { Patient-reported tenderness vs } \\
\text { CD synovitis }\end{array}$ & 1 & 38 & 8 & 243 & $\$ 4$ \\
\hline
\end{tabular}

Conclusions: Thirty-six percent of the RA patients reported flares in the hand during one year follow-up. Numbers of joints affected by swelling, tenderness or positive CD sign were low. Limited concordance between US, patient-reports and clinical examination suggests that these domains reflect different and potentially complementary aspects of inflammation in patient-reported flare.

\section{REFERENCES:}

[1] Cheung PP, et al. Arthritis Care Res 2010;62:1112.

[2] Naredo E, et al. Ann Rheum Dis 2005;64:375.

[3] Terslev L, et al. RMD Open 2017;3: e00042.

Acknowledgements: The study was supported by a grant from the Danish Rheumatism Association, the University of Southern Denmark, the Region of Southern Denmark and Knud and Edith Eriksens' Commemorative Fund.

Disclosure of Interest: None declared

DOI: 10.1136/annrheumdis-2018-eular.3553 